\title{
ВАЖНОСТЬ ЕСТЕСТВЕННОНАУЧНОГО ОБРАЗОВАНИЯ В ФОРМИРОВАНИИ КЛИНИЧЕСКОГО МЫШЛЕНИЯ ВРАЧА
}

\section{THE IMPORTANCE OF SCIENCE EDUCATION IN THE FORMATION OF THE CLINICAL THINKING OF A DOCTOR \\ T. Kolosova \\ L. Kubasova \\ I. Sychev}

Summary: This article discusses the importance of chemical education in the formation of the clinical thinking of a doctor. The study of general and bioorganic chemistry allows students to form general theoretical knowledge necessary for the subsequent development of specialized disciplines, which contributes to the emergence of clinical thinking. Teaching these disciplines at a medical university helps students develop the qualities necessary for the further improvement of clinical thinking: observation, concentration, focus, creativity, memory and intuition.

Keywords: clinical thinking, science education, general chemistry, bioorganic chemistry.
$\mathrm{M}$ ышление является основой интеллекта человека и представляет собой совокупность мыслительных операций: анализа, синтеза, сравнения, обобщения и конкретизации. Мышление реализуется в виде формулирования понятий и построения суждений и умозаключений, позволяющих найти взаимосвязи между свойствами предметов и процессами окружающего нас мира, что помогает создавать новые идеи и прогнозировать развитие событий [1].

Специалисты каждой конкретной сферы практической деятельности человека создают свои подходы к решению специфических задач, а их мышление имеет свои качественные особенности. Особенность труда врача выражается в клиническом (врачебном) мышлении специфической умственной деятельности, заключающейся в применении медицинских знаний при решении диагностических, лечебных, прогностических и профилактических задач в соответствии с особенностями, характерными для данного заболевания у конкретного больного.

Клиническое мышление требует эффективного использования теоретических знаний, практических навыков и личного опыта для сохранения здоровья конкрет-
Колосова Татьяна Юльевна

К.Х.н., дочент, ФГБОУ ВО Рязанский государственный медицинский университет Минздрава России (2. Рязань)

tkkolosova@gmail.com

Кубасова Лариса Владимировна

к.фрарм.н., доцент, ФГБОУ ВО Рязанский государственный медицинский университет Минздрава России (г. Рязань) larissa.k53@mail.ru

Сычев Игорь Анатольевич д.б.н., ФГБОУ ВО Рязанский государственный медицинский университет Минздрава России (г. Рязань)

i.sytchev@rzgmu.ru

Аннотация: В представленной статье рассматривается важность химического образования в формировании клинического мышления врача. Изучение общей и биоорганической химии позволяет сформировать у студентов теоретические знания, необходимые для последующего освоения профильных дисциплин, что способствует зарождению клинического мышления. Преподавание этих дисциплин в медицинском университете помогает развить у студентов качества, необходимые для дальнейшего совершенствования клинического мышления: наблюдательности, концентрированности, целенаправленности, творческого подхода, памяти и интуиции.

Ключевые слова: клиническое мышление, естественнонаучное образование, общая химия, биоорганическая химия.

ного пациента. Оно является дедуктивным по своей сути и имеет значимую этическую составляющую, поскольку субъектом врачебной деятельности является человек [2].

Клиническое мышление формируется в процессе практической деятельности врача. Ведущую роль в его формировании играет интеллект, который позволяет адекватно применять теоретические знания в практической работе. [3].

Клиническое мышление подразумевает формирование многочисленных связей между знаниями в области как клинических, так и естественнонаучных дисциплин. Это требует усвоения специальных знаний медико-биологического профиля и наличия у врача сформированного естественнонаучного мышления [4]. В этой статье нам хотелось бы показать, как изучение химических дисциплин в медицинском ВУЗе способствует зарождению и развитию клинического мышления.

Химическое образование студентов-медиков начинается с изучения курсов общей химии и биоорганической химии, которые создают основу для восприятия и усвоения важнейших медико-биологических дисциплин, 
таких как физиология, патофизиология, фармакология и биохимия. Так, знакомство с химической термодинамикой позволяет будущему врачу получить представление о превращениях разных видов энергии в катаболических и анаболических процессах в живых организмах. Логическим продолжением термодинамики является химическая кинетика, изучение которой способствует глубокому пониманию особенностей ферментативных реакций [5].

Изучение физико-химических свойств растворов, а именно процессов растворения и диссоциации, явлений диффузии, осмоса, действий буферных систем позволяет понять принципы функционирования клеточных мембран, формирования мембранных потенциалов, процессы гомеостаза. Для того чтобы заложить основы понимания процессов свертывания крови, изучаемых в последующих курсах, студенты знакомятся с началами коллоидной химии. Кроме того, следует отметить, что выполняя лабораторные работы в курсе общей химии, студенты-медики получают первые навыки работы с различными приборами и лабораторным оборудованием, которые используются в клинической диагностике [6].

Изучение важнейших классов органических соединений в курсе биоорганической химии дает студентам впоследствии возможность освоить фармакологическую классификацию лекарственных препаратов и их свойства. Анализ структур биополимеров: липидов, полисахаридов, пептидов и белков, нуклеиновых кислот, - способствует осмысленному пониманию связи природного строения биополимеров и их биологического действия, а также их превращений в метаболических реакциях.

Изучение общей и биоорганической химии, наряду с изучением биологии и физики на первом курсе медицинского ВУЗа способствует развитию естественнонаучного мышления, что создает базу для формирования клинического мышления и позволяет воспитать у студентов необходимые качества для его дальнейшего совершенствования.

Сформированное клиническое мышление невозможно без наблюдательности - важнейшего качества мышления врача. Выполняя практические работы по объемному анализу в курсе общей химии, студенты фиксируют точку эквивалентности по изменению цвета раствора. Это развивает цветовое зрение, которое позволяет лучше различать детали и воспринимать большее количество информационных признаков, что, несомненно, способствует формированию наблюдательности. Студенты также практикуются в развитии этого качества на практических занятиях по биоорганической химии при анализе громоздких формул биологически активных соединений с похожими структурами: моносахаридов и олигосахаридов, нуклеотидов, фосфолипидов.
Клиническое мышление предполагает наличие навыка быстрого или даже мгновенного целостного восприятия объекта. Видеть все детали во взаимосвязи студенты учатся при обсуждении химических свойств гетерофункциональных соединений - гидроксикислот, аминокислот и оксокислот.

Мышлению врача свойственна гибкость, а именно способность к быстрому изменению хода рассуждений при изменении в течении болезни. Это качество вырабатывается у студентов при самостоятельном решении ими задач в курсе общей химии после рассмотрения базовых примеров на практическом занятии.

Концентрированность и целенаправленность - важнейшие качества врача. Они помогают выделить главное при обследовании пациента и назначить ему лечение в соответствии с поставленным диагнозом. Именно с этими необходимыми качествами в значительной степени связана результативность клинического мышления [7]. При решении задач на химические превращения студентам необходимо проанализировать химические свойства представителей различных классов органических соединений, для чего необходима максимальная концентрация и целенаправленная работа.

В курсе биоорганической химии часть тем вынесена на самостоятельное изучение. Эти темы предлагаются студентам для реализации в виде проектов, которые они впоследствии защищают на практическом занятии. Создание и защита проектов вырабатывает у студентов творческий подход к осмыслению и переработке информации столь необходимый врачу в его практической деятельности.

Память - необходимое качество врача, который должен располагать информацией о значительном числе известных в настоящее время заболеваний для их успешной диагностики. Врачу также необходимо свободно ориентироваться в современных лекарственных препаратах для выбора эффективных способов лечения. Изучая общую и биоорганическую химию, студенты запоминают и накапливают большой объем фактической информации, что, несомненно, развивает их память.

Изучение химии играет определенную роль в развитии интуиции, которая необходима врачу, поскольку помогает принять решение в начальном периоде диагностического процесса. Интуиция - это продукт мысли и невозможна без большого опыта, поэтому выполнение значительного число однотипных заданий на практических занятиях способствует выработке у студентов определенного автоматизма мышления, и, следовательно, интуиции.

При изучении общей и биоорганической химии сту- 
дентами первого курса, а в дальнейшем, в результате межпредметной интеграции в условиях профессиональной направленности у будущего врача формируется системный подход к анализу и пониманию процессов, происходящих в организме человека. Это также позволяет сформировать у студентов такие необходимые для будущего врача качества, как наблюдательность, навык целостного восприятия объекта, гибкость, концентрированность, целенаправленность, творческий подход, память, интуиция. Все это является необходимым условием становления врача как профессионала [8].

\section{ЛИТЕРАТУРА}

1. Тетенев Ф.Ф., Бодрова Т.Н., Калинина О.В. Формирование и развитие клинического мышления - важнейшая задача медицинского образования // Успехи современного естествознания. - 2008. - № 4. - С. 63-65.

2. Арзуманян Н.Г., Суровикина С.А. Взаимосвязь естественнонаучного и клинического мышления // Педагогическое образование в России. - 2017. - №4. C. 18-24.

3. Тимебаев В.Н., Киселев С.В. Значение химии в формировании клинического мышления // Вятский медицинский вестник. Актуальные вопросы современной биохимии. Раздел 1. - 2007. - №4. - С. 27-29.

4. Литвинова Т.Н., Выскубова Н.К., Овчинникова С.А., Кириллова Е.Г., Слинькова Т.А. Значимость общей химии в системе медицинского образования // Фундаментальные исследования. - 2004.- №5. - С.76-77.

5. Литвинова М.Г., Литвинова Т.Н. Современный курс химии в медицинском вузе: цели, содержание, структура // Современные проблемы науки и образования. - 2018. - № 4.

6. Литвинова Т.Н. Фундаментальная химическая подготовка студентов медицинского вуза - важное звено процесса формирования современного врача // Современные наукоемкие технологии. - 2010. - № 10. - С. 206-208.

7. Литвинова Т.Н., Юдина Т.Г. Подготовка студентов медицинского вуза по химии - необходимое условие качественного образования будущего врача // Известия Самарского научного центра Российской академии наук. Педагогика. - 2010. - т. 12. - №3(2). - С. 347-351.

8. Абаев Ю.К. Клиническое мышление: учеб.-метод. пособие. Минск: БГМУ, 2008. - 60 с.

\section{(с Колосова Татьяна Юльевна (tkkolosova@gmail.com), Кубасова Лариса Владимировна (larissa.k53@mail.ru), Сычев Игорь Анатольевич (i.sytchev@rzgmu.ru). \\ Журнал «Современная наука: актуальные проблемы теории и практики»}

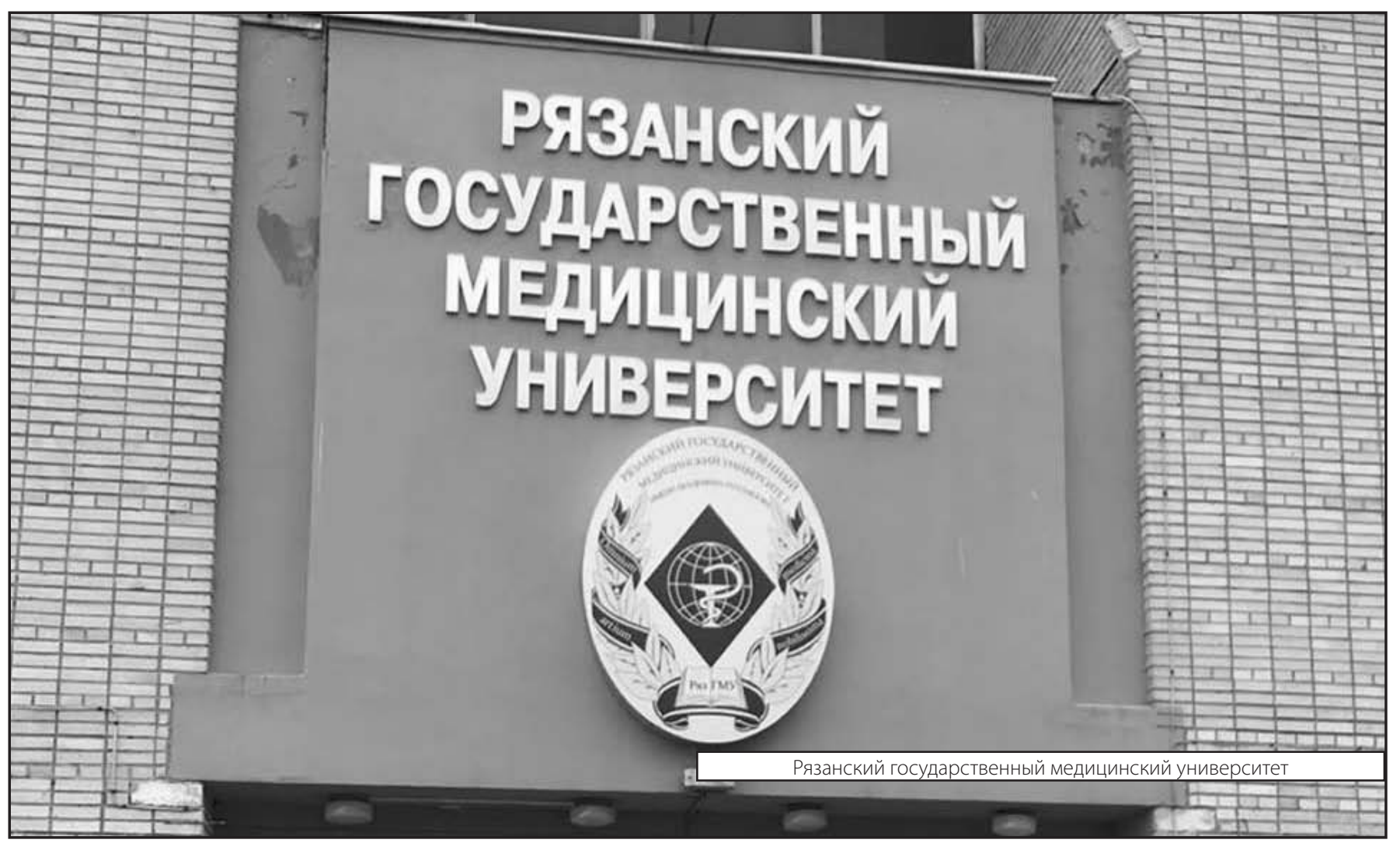

